\title{
Política de garantía de ingresos y población de origen extranjero en el País Vasco. Evidencias empíricas y deslegitimación discursiva ${ }^{1}$
}

\section{Gorka Moreno Márquez}

Ikuspegi-Observatorio Vasco de Inmigración

<gorka.moreno@ehu.eus>

\section{Maite Fouassier Zamalloa}

Ikuspegi-Observatorio Vasco de Inmigración

\section{María José Martín Herrero}

Ikuspegi-Observatorio Vasco de Inmigración
A través de este artículo, queremos indagar en el debate que se ha suscitado en los últimos tiempos en torno al uso de las prestaciones sociales en general, y de las políticas de garantía de ingresos en concreto, por parte del colectivo inmigrante de origen extranjero. Para ello, examinaremos tanto los datos empíricos referidos a la población perceptora de la renta de garantía de ingresos (RGI), ofrecidos por Lanbide-Servicio Vasco de Empleo (gestor de la $\mathrm{RGI})$, como las percepciones existentes entre la población autóctona al respecto, mediante el barómetro sobre actitudes y percepciones hacia la inmigración que elabora Ikuspegi-Observatorio Vasco de Inmigración. Partiendo del análisis de los datos estadísticos, se reflexionará en torno al discurso sobre el (ab)uso de las prestaciones sociales por parte de la población inmigrante y sus implicaciones en la deslegitimación de las políticas sociales, en general, y de las de lucha contra la exclusión social, en particular.

\section{Palabras Clave:}

Políticas sociales, inmigración, actitudes, opinión pública, agenda política.

Gizarte-politikak, immigrazioa, jarrerak, iritzi publikoa, agenda politikoa. 


\section{Introducción}

En los últimos meses, el debate en torno a las prestaciones económicas en el País Vasco ha trascendido el ámbito académico y técnico y se ha situado en el centro del debate político y social. En concreto, habría que subrayar que el ámbito que está suscitando sobremanera mayor controversia es la política de garantía de ingresos, y dentro de ésta, la renta de garantía de ingresos (en adelante, RGI).

El eje del debate se ha centrado en el uso de esta prestación económica periódica por parte del colectivo de origen extranjero, y se han discutido aspectos como el uso excesivo por parte de este colectivo, un mayor fraude entre las personas de origen extranjero, el efecto desincentivador de cara al acceso laboral, la aportación a la sociedad de estas personas o incluso a la preferencia nacional. De hecho, esta prestación está siendo uno de los temas de debate político más relevantes en la actualidad, y el seguimiento mediático que se le está haciendo ha aumentado el eco de la controversia, de tal modo que, aunque pueda parecer paradójico, gran parte de la opinión pública del País Vasco dice conocer la RGI y opina en torno a ella.

Como puede pensarse, gran parte del debate se ha estructurado sobre ciertos estereotipos y rumores que frecuentemente no son refrendados a través de los datos estadísticos disponibles. Por ello, mediante este artículo queremos profundizar en el debate. En concreto, y tras contextualizar y detallar las características de la renta de garantía de ingresos, así como su evolución y situación actual, realizaremos un análisis de los principales datos estadísticos que podemos encontrar en este ámbito. En primer lugar, examinaremos los referidos a las actitudes y percepciones de la población vasca hacia el uso de esta prestación por parte del colectivo inmigrante, para lo que nos valdremos del barómetro que anualmente realiza Ikuspegi-Observatorio Vasco de Inmigración. En segundo lugar, analizaremos los datos referidos a la RGI que ofrece Lanbide-Servicio Vasco de Empleo, que es la institución dependiente del Gobierno Vasco que la gestiona y tramita. Junto a la exposición de estos datos, se hará también una interpretación, incidiendo en aspectos que frecuentemente son obviados en el debate social. Por último, en el apartado de conclusiones plantearemos una serie de reflexiones en torno a este debate que tienen por objetivo contextualizarlo y, a su vez, intentar profundizar e indagar en los factores que lo han desencadenado, así como en sus posibles consecuencias a corto y medio plazo.

\section{Antecedentes: la renta de garantía de ingresos}

La renta de garantía de ingresos de la Comunidad Autónoma del País Vasco (CAPV) inició su andadura en 1989, con la denominación de ingreso mínimo de familiar (García Romero, 1999) y al amparo del modelo francés de rentas mínimas creado en 1988. El País Vasco se sitúa así dentro de los países europeos que en las últimas décadas han instaurado algún modelo de este tipo (Castel, 1997) para la reconfiguración de sus Estados del bienestar (Ayala, 2000).

En ámbito estatal, fue el primer modelo de rentas mínimas que se instauró, y posteriormente se fueron desarrollando el resto de modelos autonómicos (Cabases y Montserrat, 1991). Los diferentes modelos muestran una gran heterogeneidad y diversidad (Roberts, 2001; Gaviria y González, 2002), que hacen que difícilmente se pueda hablar de un modelo español de rentas mínimas. Además si tenemos en cuenta las características de cada uno de ellos, veremos que son muy pocos los que realmente pueden considerarse como programas de rentas mínimas o de garantía de ingresos, ya sea por su escasa cuantía económica, su limitada cobertura a personas potencialmente perceptoras o por los requisitos establecidos (Rodríguez Cabrero, 2009). De hecho, se estima que dichos programas tan sólo cubren al $17 \%$ del total de la población española que se encuentra en situación de pobreza severa (Laparra y Ayala, 2009: 32).

El modelo vasco, que ha tenido varias denominaciones a lo largo del tiempo -ingreso mínimo de inserción (1989-2000), renta básica (2000-2008)-, se conoce en la actualidad como renta de garantía de ingresos, y existe un amplio consenso en que es el único modelo equivalente a los sistemas de protección de este tipo que pueden encontrarse en otros países europeos (Moreno y Fullaondo, 2003; Laparra, $2004 \mathrm{~b}$ ). El gasto anual por habitante en programas de rentas mínimas en Alemania es de 183 euros, de 174 en Francia, de 153 en el Reino Unido, de 163 en el País Vasco y tan sólo de 11,4 euros en el conjunto de España -sin el País Vasco-. De igual forma, la cobertura de estas prestaciones es de 4,2 personas por cada cien en Alemania, 33 en Francia, 2,8 en el Reino Unido, 3,1 en el País Vasco y de 0,3 en España (SIIS Centro de Documentación y Estudios, 2014).

Todos estos datos no hacen más que ilustrar las diferencias existentes entre el modelo vasco y el del resto de comunidades autónomas. Así, según estimaciones del propio Gobierno de España, la cobertura del modelo vasco es seis veces mayor que la que se da en otras comunidades (Ministerio de Trabajo y Asuntos Sociales, 2005). En esta misma línea, es interesante destacar que se estima que, del total del gasto en rentas mínimas a escala estatal, el $40 \%$ corresponde a la Comunidad Autónoma Vasca, con un peso de menos del $5 \%$ sobre el total de la población española y además una de las tasas de pobreza más bajas de todo el territorio.

Desde la aprobación de la Ley para la Garantía de Ingresos y para la Inclusión Social (2008), y su posterior reforma en 2011, para poder percibir la RGI se han de cumplir los siguientes supuestos:

- Haber constituido una unidad convivencial al menos un año antes de solicitar la prestación. 
- Estar empadronado y residir realmente en la CAPV durante al menos tres años antes de cursar la solicitud

- No tener ingresos superiores a la cuantía establecida para cada caso.

- Tener más de 23 años, a no ser que se cumpla alguna de las excepciones - descendientes a cargo de la persona solicitante o sufrir violencia de género, por ejemplo-.

Con respecto a la cuantía, cabe subrayar que a día de hoy una unidad convivencial formada por una única persona percibe el $81 \%$ del salario mínimo interprofesional si está en edad laboral $(616,17$ euros) y el $100 \%$ si tiene más de 65 años (700,15 euros). Una unidad compuesta por dos personas, 791,17 y 875,19 euros, respectivamente; y una de tres o más personas, 875,19 y 945,20 euros. A estas cantidades hay que sumar el complemento de vivienda si la persona titular tiene que pagar un alquiler o un préstamo; dicho complemento se sitúa, de media, entre 200 y 225 euros.

La RGI es una prestación que complementa otro tipo de ingresos; por ello es importante destacar que las cuantías citadas en el párrafo anterior son para personas sin ningún tipo de ingresos y que, si existen otros ingresos, la RGI complementa la cuantía percibida inicialmente hasta las cifras citadas. En el caso de las personas pensionistas, por ejemplo, aunque pueden ser perceptoras de RGI, la cuantía correspondiente suele ser limitada.

También existe un complemento para familias monoparentales e incentivos al empleo, que tienen como función evitar la desincentivación del acceso al mercado laboral, y que hacen que durante tres años una parte de los ingresos derivados del empleo queden exentos para el cómputo de la RGI.

Con respecto a la evolución de los datos, es destacable que tanto el gasto como el número de personas perceptoras han mostrado un incremento exponencial a lo largo del tiempo. En 2000, por ejemplo, había 13.000 personas perceptoras de la en aquel momento conocida como renta básica (SIIS Centro de Documentación y Estudios, 2002: 16). A finales de 2009, eran 48.449; y en la actualidad, la cifra se sitúa en torno a las 65.000 personas titulares, aunque el número de beneficiarias que viven de esta prestación es sensiblemente mayor. El gasto ha seguido una tendencia similar, de tal forma que en 1989 era de 4,2 millones de euros, de 197,3 en 2008 , y de en torno a 360 millones de euros en la RGI -unos 435 si sumamos el coste del complemento de vivienda-.

\section{Datos y metodología}

Los resultados de este artículo se centrarán en el análisis cuantitativo de datos estadísticos relacionados con la renta de garantía de ingresos y el uso de ésta por parte de colectivo de origen extranjero.
Los datos proceden tanto de fuentes primarias como secundarias:

- En primer lugar, hemos utilizado datos primarios obtenidos por Ikuspegi-Observatorio Vasco de Inmigración en el barómetro sobre actitudes y percepciones hacia la inmigración que realiza todos los años. Exactamente, presentamos los datos referidos a la RGI y la población inmigrante para el año 2013.

- En segundo lugar, utilizamos los datos ofrecidos por Lanbide-Servicio Vasco de Empleo, que es la institución que gestiona la RGI, respecto al número de personas perceptoras y su procedencia. Los datos utilizados son de 2014 y se refieren a personas de origen extranjero.

- Por último, también se analizarán datos de la Encuesta de Pobreza y Desigualdades Sociales en el País Vasco (EPDS) [Eustat] en su edición de 2014, para así poder examinar el nivel de pobreza y el origen de la persona. En este caso, los datos disponibles se refieren a población con nacionalidad extranjera, de tal modo que no podemos desagregar a aquellas personas de origen extranjero que han obtenido la nacionalidad española.

En uno de los apartados de resultados, se relacionan los datos de personas perceptoras con los de la población residente en la CAPV (padrón a 1 de enero de 2014), para estimar la tasa de percepción según el origen. En este sentido, cabe destacar que los datos ofrecidos por Lanbide hacen referencia a personas titulares y no beneficiarias, por lo que somos conscientes de que esta tasa es menor que la real y muestra ciertas debilidades. En todo caso, entendemos que es interesante para profundizar y aprehender mejor el grado de percepción de RGI, siendo conscientes en todo momento de las limitaciones de esta operación estadística.

\section{Resultados}

\subsection{Percepción sobre el uso de la renta de garantía de ingresos por parte de la población inmigrante}

Desde 2011, el barómetro sobre actitudes y percepción hacia la población inmigrante que realiza Ikuspegi-Observatorio Vasco de Inmigración recoge la opinión sobre el uso de la RGI por parte de la población inmigrante. En concreto, se pregunta sobre qué requisitos deberían cumplir estas personas para acceder a dicha prestación, sobre si se benefician excesivamente de la RGI, o sobre si ésta desincentiva su búsqueda de trabajo y acceso al mercado laboral.

Con respecto a la primera de las cuestiones, un $14,7 \%$ estima que la RGI sólo debería darse a población autóctona. Este porcentaje, aunque no es mayoritario, ha ido creciendo a lo largo de estos últimos tres años. Por su parte, la prioridad de la población autóctona frente a la extranjera para el acceso a la RGI concita un $\mathbf{2 9 , 2} \%$ del total de las respuestas 


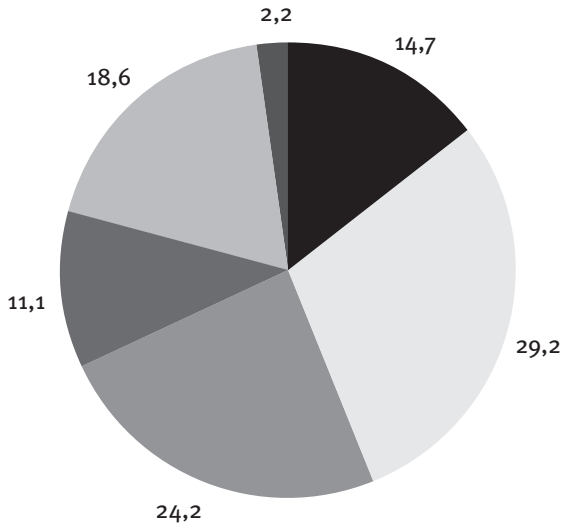

Las personas inmigrantes no deberían tener acceso, ninguno, a percibir la renta de garantía de ingresos: debería ser sólo para autóctonos.

Todas las personas inmigrantes deberían tener acceso a la renta de garantía de ingresos, pero después de percibirla todos los autóctonos que la necesiten.

La renta de garantía de ingresos debería ser un servicio al que sólo tuvieran acceso los inmigrantes en situación administrativa regular.

Las personas inmigrantes deberían acceder a la renta básica en las mismas condiciones que la población autóctona.

Las personas inmigrantes deberían acceder a la renta de garantía de ingresos en las mismas condiciones anteriores, es decir, cumpliendo un año de empadronamiento.

Todas las personas, autóctonas e inmigrantes, deberían poder acceder a la RGI si lo necesitan, independientemente del tiempo de empadronamiento.

$\mathrm{Ns} / \mathrm{Nc}$

Fuente: Ikuspegi-Observatorio Vasco de Inmigración.

Gráfico 2. Evolución del grado de acuerdo con la percepción de un uso abusivo de la renta de garantía de ingresos por parte del colectivo inmigrante. CAPV, 2011-2013 (\%)

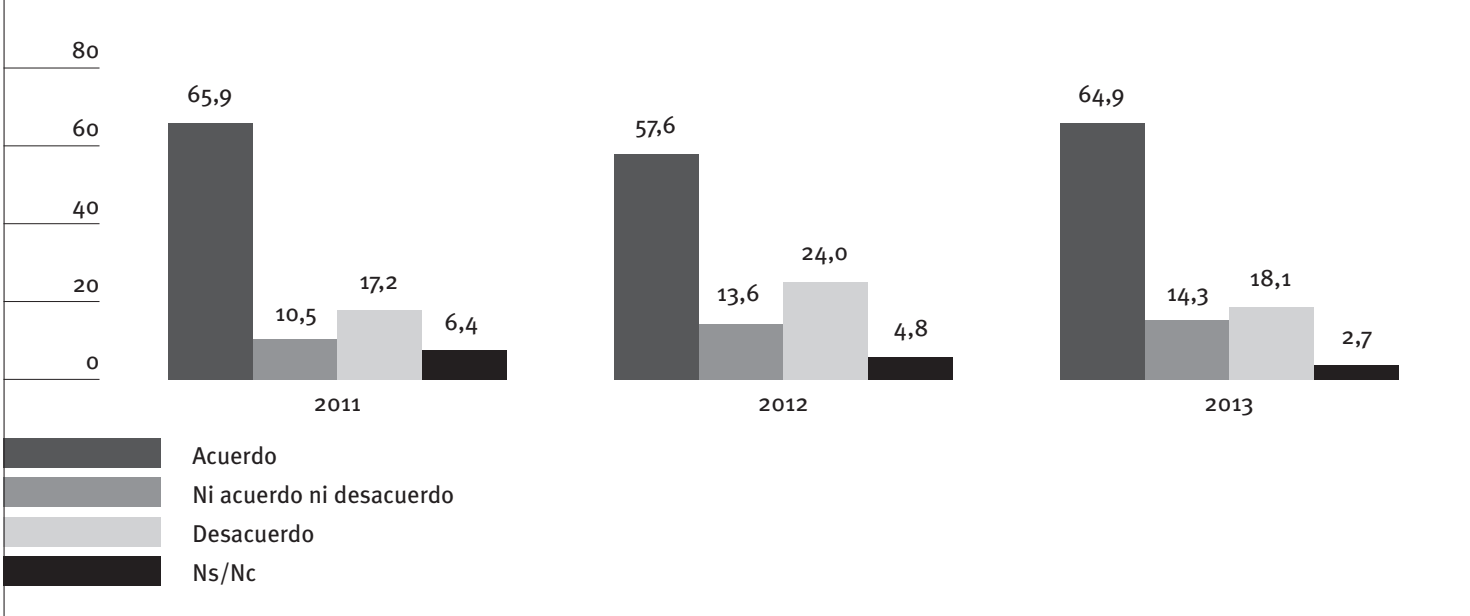

Fuente: Ikuspegi-Observatorio Vasco de Inmigración.

y es, por tanto, la opción con más peso entre todas las posibles. Un $24,2 \%$ de la población vasca estima, en cambio, que la población extranjera en situación irregular no debería tener derecho a percibirla (en la actualidad, en torno a 3.717 personas titulares de RG están en situación administrativa irregular, lo que supone un 5,7\% del total de perceptoras y un 35,9\% de la población extranjera titular de RGI). Por último, las dos respuestas que plantean un acceso similar entre la población autóctona y la extranjera suponen el $29,7 \%$ del total: un $11,1 \%$ estima que el requisito del empadronamiento tendría que flexibilizarse y pasar a ser de un año, como sucedía hasta 2012; y un $18,6 \%$ estima que el empadronamiento como requisito debería desaparecer (Gráfico 1 ).
Todas las respuestas que demandan un endurecimiento de los criterios de acceso a la RGI para la población extranjera suponen el 68,1\% del total de la población vasca, frente al ya citado $29,7 \%$ que plantea el mantenimiento de los requisitos o incluso una cierta flexibilización de éstos.

En otro orden de cosas, también se pregunta en el barómetro acerca de ciertos estereotipos asociados al uso de las prestaciones sociales, pero en este caso centrados en el colectivo inmigrante. Se demanda la opinión en torno a dos de ellos: el uso abusivo de la RGI por parte del colectivo inmigrante y la posible desincentivación que produce en la búsqueda de empleo. Con respecto a la primera de las 


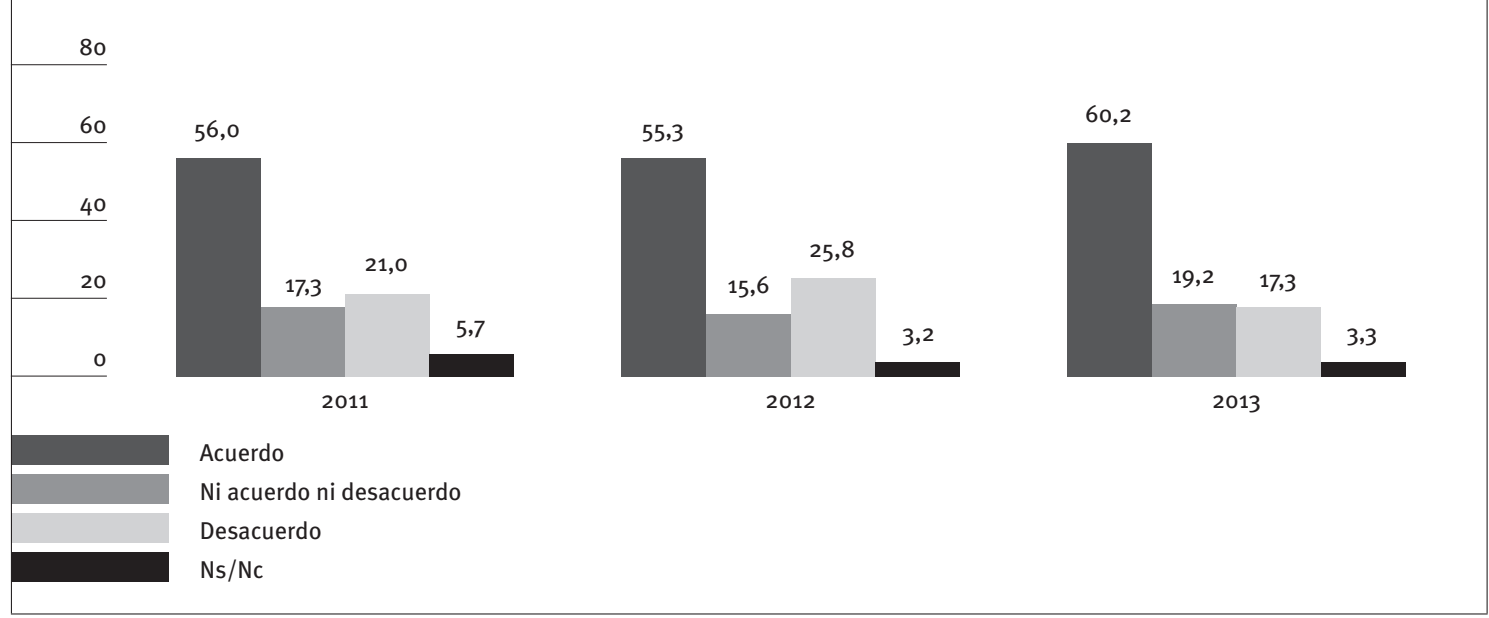

Fuente: Ikuspegi-Observatorio Vasco de Inmigración.

cuestiones, aunque en 2012 se percibe un descenso de la opinión favorable al estereotipo que asocia un uso excesivo de la RGI a la población inmigrante, los datos se mantienen bastante estables en el tiempo, y casi dos tercios de la población vasca están de acuerdo con esta opinión. En concreto, en 2013 un $64,9 \%$ estima que hacen un uso excesivo de aquélla, frente al $18 \%$ que no está de acuerdo con esa afirmación (Gráfico 2).

Con respecto al efecto desincentivador de la RGI entre el colectivo inmigrante, se mantiene la pauta ya indicada y una gran parte de la población vasca estima que esa realidad ocurre: un 60,2\% está de acuerdo con la afirmación, porcentaje algo superior al de los años anteriores. De igual forma, es resaltable que el porcentaje de personas que están en desacuerdo desciende sensiblemente de 2012 al 2013, pasando del 25,8\% al 17,3\% (Gráfico 3).

Como podemos observar, en torno a dos tercios de la población vasca autóctona cree que los requisitos de la RGI tendrían que endurecerse para el colectivo inmigrante, y que además hace un uso excesivo de aquélla y se convierte en un obstáculo para la búsqueda de empleo de estas personas.

\subsection{Datos referidos al perfil de las personas titulares de renta de garantía de ingresos}

Según los datos disponibles a octubre de 2014, había en la CAPV 65.479 personas titulares de RGI. De ellas, 43.713 habían nacido en el Estado (63,7\% del total) y 23.515 (35,9\%), en el extranjero. Como puede observarse, en torno a dos tercios eran de origen español y un tercio, de origen extranjero. En todo caso, no podemos dejar a un lado que hay un importante número de personas jubiladas que perciben la RGI como consecuencia de las debilidades que muestran tanto el sistema contributivo de pensiones como el no contributivo y que, como puede pensarse, la inmensa mayoría de ellas son de origen español.

Si las excluimos y tan sólo tenemos en cuenta el número de titulares de RGI hasta los 65 años, podemos observar que los datos varían con respecto a los presentados en el párrafo anterior. En concreto, hay 12.485 personas de más de 65 años (suponen el 19,1\% del total). De éstas, 12.153 poseen la nacionalidad española y 331 son extranjeras (no disponemos del lugar de nacimiento). Así, tendríamos a 31.560 personas de origen español y a 23.184 extranjeras, que suponen, respectivamente, el $57,6 \%$ y el $42,3 \%$ del total de la población en edad laboral (Gráfico 4).

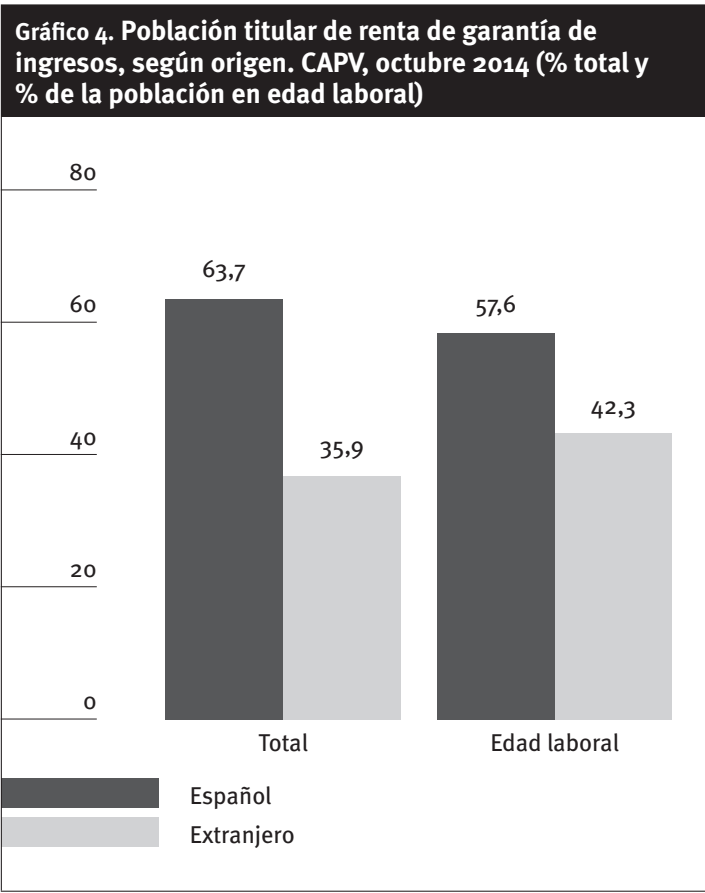

Fuente: Elaboración propia a partir de datos de Lanbide. 
Tabla 1. Población de origen extranjero titular de renta de garantía de ingresos, por origen y sexo. CAPV, octubre 2014

\begin{tabular}{|l|c|c|c|c|c|}
\cline { 2 - 6 } \multicolumn{1}{c|}{} & \multicolumn{2}{c|}{ Total } & Hombre & \multicolumn{2}{c|}{ Mujer } \\
\cline { 2 - 6 } \multicolumn{1}{c|}{} & $\mathbf{N}$ & $\%$ & $\mathbf{N}$ & $\mathbf{N}$ & \multicolumn{1}{c|}{$\%$} \\
\hline Apátrida & 20 & 0,1 & 8 & 12 & 60,0 \\
\hline Unión Europea & 2.150 & 9,1 & 786 & 1.364 & 63,4 \\
\hline Resto de Europa & 607 & 2,6 & 215 & 392 & 64,6 \\
\hline Magreb & 6.339 & 27,0 & 4.592 & 1.747 & 27,6 \\
\hline África Subsahariana & 4.026 & 17,1 & 2.779 & 1.247 & 31,0 \\
\hline Asia & 1.131 & 4,8 & 981 & 150 & 13,3 \\
\hline América del Norte & 10 & 0,0 & $<5$ & 8 & 80,0 \\
\hline América del Sur & 9.168 & 39,0 & 2.299 & 6.869 & 74,9 \\
\hline Oceanía & 64 & 0,3 & 27 & 37 & 57,8 \\
\hline Total & 23.515 & 100,0 & 11.687 & 11.826 & 50,3 \\
\hline
\end{tabular}

Fuente: Elaboración propia a partir de datos de Lanbide.

Si analizamos únicamente los datos referidos a la población de origen extranjero, puede observarse que casi un $40 \%$ de las personas titulares de RGI de origen extranjero proceden de Latinoamérica, seguidas de las que proceden del Magreb (27\%), de África Subsahariana $(17,1 \%)$ y de otras procedencias con un menor peso, como la Unión Europea (9,1\%) 0 Asia (4,8\%). Los tres principales orígenes suman un $83,1 \%$ del total, y si agrupamos las dos procedencias africanas, podemos ver que suponen el $44,1 \%$, por encima incluso del origen latinoamericano (Tabla 1).

Por sexo, tomando la población extranjera en su conjunto se da un equilibrio casi perfecto, pues el $50,3 \%$ son mujeres, un dato que muestra una sensible diferencia con respecto a la población española, en la que las mujeres suponen el 61,8\%. Este dato se explica sobre todo por el gran peso de población africana dentro de las personas titulares de RGI y por el peso mayoritario de los hombres dentro de este origen, tal y como puede verse en la Tabla 1.

Las diferencias que se aprecian según el origen son también muy llamativas, ya que mientras que la población latinoamericana es eminentemente femenina $(74,9 \%)$, este porcentaje desciende mucho para las originarias de África (Magreb, 27,6\%; África Subsahariana, $31 \%$ ).

Estos datos deben ponerse en relación con el peso de estos orígenes dentro de la población extranjera en general (Gráfico 5), para así poder analizarlos con mayor profundidad. En este caso, podemos observar cómo aparecen importantes diferencias según el peso de cada colectivo dentro de la población titular de RGI. Destaca notoriamente una sobrerrepresentación en la RGI de la población de origen africano: 13,6 puntos porcentuales para el Magreb y 10,2 para el África Subsahariana. En el lado opuesto, se sitúan las personas procedentes de Latinoamérica (7,1 puntos porcentuales menos en la RGI que en el padrón) y la Unión Europea $(12,7$ puntos). Estos datos apuntan claramente a una mayor percepción entre la población de origen africano, que concuerda con los datos disponibles al respecto, los cuales indican que esta procedencia es la que sufre una mayor precariedad y vulnerabilidad social (Moreno y Fullaondo, 2013).

Gráfico 5 . Relación de la población de origen extranjero, según su peso en la renta de garantía de ingresos y el padrón. CAPV, 2014 (\%)

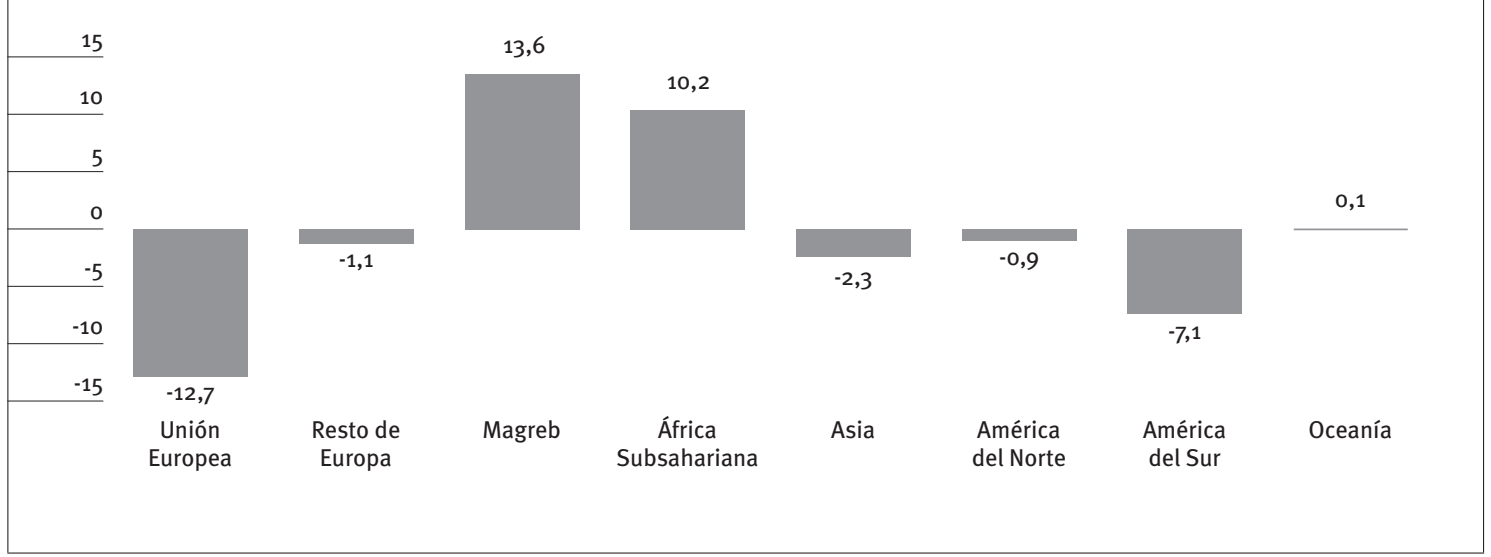

Fuente: Elaboración propia a partir de datos de Lanbide e INE. 


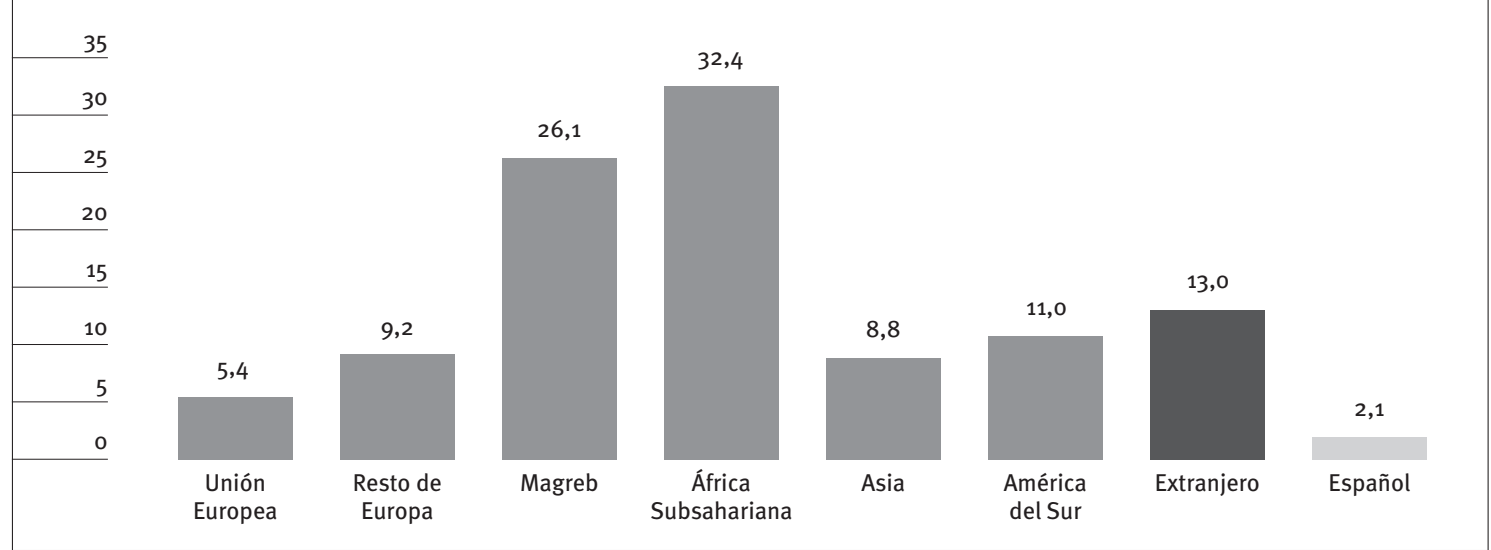

Fuente: Elaboración propia a partir de datos de Lanbide e INE.

Esta dinámica también puede detectarse si realizamos una estimación de la tasa de percepción de la RGI según procedencia². Así, dicha tasa se sitúa en un $13 \%$ para el conjunto de la población de origen extranjero, frente al $2,1 \%$ de la población nacida en España. Este dato incide de nuevo en una realidad en la que dentro de la sociedad vasca el espacio social de la pobreza estaría copado por la población de origen extranjero y en el que la población de origen español por debajo del umbral de la pobreza es muy limitado.

Analizando dicha tasa según el origen de la población extranjera, también pueden vislumbrarse importantes diferencias. A través de esta estimación, se confirma el mayor uso de la RGI por la población de origen africano, con tasas de más del $25 \%(26,1 \%$ para la población magrebí y $32,4 \%$ para la subsahariana). El resto de orígenes se sitúan por debajo de la media y con porcentajes que oscilan entre el $11 \%$ de la población latinoamericana y el 5,4\% de la de población de la Unión Europea.

\section{Conclusión y algunas reflexiones para el debate}

Los datos que hemos presentado en este artículo indican, por un lado, que la percepción negativa del uso de la RGI por parte del colectivo inmigrante está bastante arraigada y extendida en un importante sector de la población vasca. Las cifras referidas a la percepción de la RGI por parte de la población inmigrante, de forma descontextualizada, no vienen más que a reforzar esas actitudes reacias o negativas hacia el uso de esta prestación o sobre la necesidad de un endurecimiento de los requisitos de acceso.

${ }^{2}$ Como ya hemos apuntado, esta tasa muestra algunas debilidades estadísticas, ya que los datos del padrón se refieren a 1 de enero de 2014 y los de la RGI, a octubre de ese año. Del mismo modo, se pone en relación el conjunto de la población residente en la CAPV con las personas titulares, pero no con las beneficiarias, por lo que las cifras resultantes son menores que las tasas reales de percepción.
Sin embargo, no podemos obviar que el espacio social de la pobreza en el País Vasco en la actualidad está copado por la población de origen extranjero y, lógicamente, este hecho hace que su peso en la RGI sea considerablemente mayor que en el conjunto de la sociedad.

Así, si tomamos como referencia los datos recientes que ofrece la Encuesta de Pobreza y Desigualdades Sociales en el País Vasco (Eustat), en 2014 la tasa de pobreza del colectivo inmigrante de origen extranjero se sitúa en el $36 \%$, mientras que es de un $4 \%$ para la población autóctona. De igual forma, las personas inmigrantes suponen el 36,4\% de la población en situación de pobreza en la CAPV, frente al 63,6\% de personas de origen español, unos porcentajes prácticamente idénticos al peso de estos dos colectivos en la RGI (35,9\% para la población extranjera y 63,7\% para la española).

Dicho de otro modo, la población extranjera y la española tienen, dentro de la RGI, un fiel reflejo del peso de la pobreza en ambos colectivos y, por lo tanto, las cifras y las diferencias que se dan entre unos y otros no son para nada sorprendentes, más aún si tenemos en cuenta que la RGI es una medida que se dirige precisamente a atender a aquellas personas que se sitúan por debajo del umbral de la pobreza o en una situación de vulnerabilidad social. Del mismo modo, no es nada sorprendente que aquellos colectivos de origen extranjero que sufren la pobreza con mayor intensidad -los procedentes del Magreb y África Subsahariana- sean precisamente los que perciben en mayor medida la RGI.

Sin embargo, el caldo de cultivo que suponen las percepciones que hemos citado en este trabajo y una mayor animadversión hacia colectivos como el magrebí y el africano, en general, unidos a un análisis de los datos totalmente descontextualizador y tendencioso, han hecho que, en estos momentos, en la CAPV se haya dado una especie de 'tormenta perfecta' en torno al debate sobre la RGI. De hecho, el epicentro de esta controversia 
se sitúa en Vitoria-Gasteiz, una ciudad en la que el peso de la población inmigrante dentro de la RGI es mayor que en el conjunto de la CAPV, y también superior el peso de población de origen africano, sobre todo magrebí.

En el análisis de las actitudes hacia la inmigración, se subraya frecuentemente la relevancia del discurso político y su influencia en la opinión pública de cara a no crear espacios de impunidad en los que la población se pueda ver legitimada para pasar de la actitud al comportamiento (Fouassier et al., 2014). De hecho, en estos momentos podemos subrayar que los espacios de impunidad frente a la inmigración han aumentado en el País Vasco y que ciertos discursos están alterando en cierto grado la convivencia ciudadana. Hasta ahora no ha ocurrido ningún hecho destacable, pero se percibe una cierta crispación social en torno a este debate.

Al respecto, también es destacable el papel que está jugando la inmensa mayoría de la clase política y de los partidos políticos vascos, que han decidido no dejarse influir por discursos más reacios hacia la RGI y están llevando a cabo tanto un discurso como una práctica de legitimación y apoyo sin fisuras a la RGI y a lo que supone en el País Vasco, lo cual limita también los posibles espacios de impunidad y posibilita una especie de 'cordón sanitario’ o ‘cinturón de acero' frente a discursos contrarios tanto hacia la RGI como hacia el colectivo inmigrante.

En este sentido, tal y como hemos apuntado a lo largo de este artículo, no puede dejarse a un lado que el conjunto del sistema de garantía de ingresos vasco, y la RGI como medida nuclear, son el estandarte del modelo social vasco y una de las principales herramientas que hacen que las tasas de pobreza sean sensiblemente más bajas que en otros territorios -más allá de otros factores estructurales, que también influyen-y son un modelo que se equipara a los sistemas de protección social más avanzados de Europa. El riesgo de deslegitimar el modelo a través del colectivo inmigrante es el de deslegitimar también el modelo en su conjunto, con lo que ello conlleva en términos de cohesión social. 
(2011): “Ley 4/2011, de 24 de noviembre, de modificación de la Ley para la Garantía de Ingresos y para la Inclusión Social”, Boletín Oficial del País Vasco, n- 233, 12-12-2011 [rhttp://www.euskadi.net/ cgi-bin_k54/ver_c?CMD $=$ VERDOC\&BASE $=$ Bo $3 A \& D O C N=000087384 \& C O N F=/$ config $/ k_{54} /$ bopv_c.cnf>].

(2008): “Ley 18/2008, de 23 de diciembre, para la Garantía de Ingresos y para la Inclusión Social", Boletín Oficial del País Vasco, $\mathrm{n}-250$, 31-122008, págs. 32.729-32.804 [<http://www. lehendakaritza.ejgv.euskadi.net/r48-vacia/es/ bopv2/datos/2008/12/0807235a.pdf)].

AYALA, L. (2000): Las rentas mínimas en la reestructuración de los Estados de bienestar, Madrid, Consejo Económico y Social.

CABASES, J. M.; y MONTSERRAT, J. (1991): “Análisis económico de la implantación de la renta mínima garantizada", en BETOLAZA, J. I. (coord.), Nuevas necesidades. Nuevas prestaciones. Cuartas Jornadas de Economía de los Servicios Sociales, Vitoria-Gasteiz 21 al 23 de marzo de 1990, Barcelona, Asociación de Economía de la Salud.

CASTEL, R. (1997): Las metamorfosis de la cuestión social. Una crónica del salariado, Buenos Aires, Paidós.

EUSTAT (2014): Encuesta de Pobreza y Desigualdades Sociales.

FOUASSIER, M. et al. (2014): "Combatiendo los discursos xenófobos. La estrategia Zurrumurrurik Ez! / Antirumores Getxo" [inédito], Congreso Internacional '¿Qué dicen las ciencias sociales sobre la crisis?', Bilbao, 14-15 de julio de 2014

GARCÍA ROMERO, M. B. (1999): Rentas mínimas garantizadas en la Unión Europea, Madrid, Consejo Económico y Social.
GAVIRIA, L.; y GONZÁLEZ, F. (2002): Propuestas integradas de políticas activas de bienestar y empleo: sumario, Dublín, Fundación Europea para la Mejora de las Condiciones de Vida y de Trabajo [shttp:// www.ceet.es/redinclusionsocial/wp-content/ uploads/2011/08/Propuestas-integradasempleo-y-bienestar-Espa\%C3\%B1a.pdf $>$ ].

INE (2014): Estadística del padrón continuo.

LAPARRA, M. (2004a): "Las rentas mínimas en España” [inédito], Encuentro 'Renta básica y procesos de inserción', Vitoria-Gasteiz, 1-2 diciembre.

- (2004b): "La travesía del desierto de las rentas mínimas en España", Documentación Social, nํㅜ 135, págs. 57-76.

LAPARRA, M.; y AYALA, L. (2009): El sistema de garantía de ingresos mínimos en España y la respuesta urgente que requiere la crisis social, Madrid, Fundación Foessa.

MINISTERIO DE TRABAJO Y ASUNTOS SOCIALES (2005): III Plan Nacional de Acción para la Inclusión Social del Reino de España. 2005-2006 [rhttp://ec.europa.eu/employment_social/ social_inclusion/docs/2005/es_es.pdf)].

MORENO, G.; y FULLAONDO, A. (2013): “La evolución del proceso de integración del colectivo inmigrante en la Comunidad Autónoma del País Vasco", en BLANCO, C.; MORENO, G.; y COLLADO, J. (coords.): VII Congreso Migraciones Internacionales en España, Bilbao, Universidad del País Vasco.

MORENO, L. et al. (2003): ¿Existe una 'malla de seguridad' en la Europa del Sur. La lucha con pobreza y la exclusión en España, Grecia, Italia y Portugal, serie Documentos de Trabajo, no 03-17, CSIC, Unidad de Políticas Comparadas [ [http://hdl. handle.net/10261/1579']. 
ROBERTS, E. (2001): “Coordination of activation programmes for minimum income recipients. European experiences: a synthesis" [inédito], Workshop 'Social Exclusion, Minimum Income Support and Workfare in Europe', Helsinki, 28 de agosto a 1 de septiembre [<http://www. researchgate.net/publication/237690005 Coordination_of_activation_programmes_ for_minimum_income_recipients_European_ experiences_a_synthesis»].
RODRÍGUEZ CABRERO, G. (2009): Valoración de los programas de rentas mínimas en España, Comisión Europea, Dirección de Empleo, Asuntos Sociales e Igualdad de Oportunidades [<http://ec.europa.eu/social/BlobServlet?docl $\mathrm{d}=9043$ \&langld $=e s\rangle]$.

SIIS CENTRO DE DOCUMENTACIÓN Y ESTUDIOS (2014): "Datos comparativos de programas de rentas mínimas en Europa" [inédito].

- (2002): "Dos de cada 100 familias vascas cobran la renta básica”, Hilero Eguneratuz, noำ19, pág. 16. 